\title{
Selected papers from the workshop of the GOR Working Group Decision Theory and Applications 2017
}

\author{
M. J. Geiger ${ }^{2}$ (D) R. Vetschera ${ }^{1}$
}

Published online: 26 December 2018

(c) The Author(s) 2018

In 2017, the Working Group "Decision Theory and Practice" of GOR e.V., the German Operations Research Society, celebrated the 25th anniversary of the Working Group by holding a workshop at University of Vienna on February 27/28, 2017. The Workshop was organized by Rudolf Vetschera, University of Vienna, who was also organizer of the group's first event in Konstanz in 1992.

In total 12 presentations were given at the workshop. The topics covered a wide spectrum of both theoretical developments in fields such as combinatorial multicriteria optimization or decision making under risk, to empirical studies on behavior and biases in decision making, and applications of decision models in fields such as healthcare, sports, and environmental problems.

CEJOR has a tradition of publishing special issues from OR workshops (e.g., Povh et al. 2017; Zekic-Sušac et al. 2018; Csendes et al. 2017). Unfortunately, it was not possible to create a full special issue of CEJOR from this workshop, since several participants had already submitted their work elsewhere. Nevertheless, we are happy to present two papers, which, after passing through CEJOR's usual review process, are now combined as a feature section in a regular issue. These two papers cover quite different topics. Thus, they show on the one hand the range of topics that the GOR Working Group deals with. On the other hand, they also fit nicely into the publishing tradition of CEJOR and thus also show the high degree of overlap between CEJOR's editorial policy and the topics addressed by the working group.

Schröder et al. (2019) describe the application of the RPROMETHEE multicriteria method to evaluate different pathways how biomass can be converted into usable energy that can be used e.g. in transportation to power vehicles. The paper thus continues the tradition of CEJOR to deal with problems of environmental management and energy (Bohanec et al. 2017) and that apply and analyze methods of multicriteria

\footnotetext{
$\bowtie$ R. Vetschera

rudolf.vetschera@univie.ac.at

M. J. Geiger

m.j.geiger@hsu-hh.de

1 University of Vienna, Vienna, Austria

2 University of the Federal Armed Forces Hamburg, Hamburg, Germany
} 
decision making (Peric et al. 2018; Trdin and Bohanec 2018). The paper not only provides an interesting application of multicriteria decision making methods to an important environmental topic, but it also introduces a new approach for the visual representation of results of such methods, that is not only applicable to PROMETHEE, but also to many other similar methods.

The second paper in this section, Köster et al. (2019) address the modeling of behavioral issues in the Newsvendor problem, which is a regular topic also for CEJOR (Gaspars-Wieloch 2017; Kaya and Caner 2018). Their paper is particularly interesting from a methodological point of view. They use simulation to represent the behavior of boundedly rational decision makers in a newsvendor model, and study whether behavior that exactly corresponds to one possible behavioral model could, in an empirical study, also be mistakenly interpreted as resulting from a different behavior. The article shows that misinterpretations of empirical results are indeed possible, but that there are also marked differences between models in terms of vulnerability to such phenomena.

We hope that this section provides the readers with at least some impression of the work of the GOR Working Group on Decision Theory and Application, that motivates some readers to participate in future workshops and become active members of the working group, and that it encourages more working group members to publish their work in CEJOR, which provides a close match to topics discussed in the group.

Acknowledgments Open access funding provided by University of Vienna.

Open Access This article is distributed under the terms of the Creative Commons Attribution 4.0 International License (http://creativecommons.org/licenses/by/4.0/), which permits unrestricted use, distribution, and reproduction in any medium, provided you give appropriate credit to the original author(s) and the source, provide a link to the Creative Commons license, and indicate if changes were made.

\section{References}

Bohanec M, Trdin N, Kontić B (2017) A qualitative multi-criteria modelling approach to the assessment of electric energy production technologies in Slovenia. Cent Eur J Oper Res 25:611-625

Csendes T, Imreh C, Temesi J (2017) Editorial, special issue on VOCAL, Hungarian OR conference and ESI 2015. Cent Eur J Oper Res 25:739-741

Gaspars-Wieloch H (2017) Newsvendor problem under complete uncertainty: a case of innovative products. Cent Eur J Oper Res 25:561-585

Kaya O, Caner S (2018) Supply chain contracts for capacity decisions under symmetric and asymmetric information. Cent Eur J Oper Res 26:67-92

Köster C, Schenk-Mathes H, Specht C (2019) Explanatory power of behavioral models in the newsvendor problem: a simulation study. Cent Eur J Oper Res (this issue)

Perić T, Babić Z, Matejaš J (2018) Comparative analysis of application efficiency of two iterative multi objective linear programming methods (MP method and STEM method). Cent Eur J Oper Res 26:565-583

Povh J, Stirn LZ, Žerovnik J (2017) Editorial, special issue of slovenian society INFORMATIKA. Cent Eur J Oper Res 25:521-523

Schröder T, Lauven L-P, Beyer B, Lerche N, Geldermann J (2019) Using PROMETHEE to assess bioenergy pathways. Cent Eur J Oper Res (this issue)

Trdin N, Bohanec M (2018) Extending the multi-criteria decision making method DEX with numeric attributes, value distributions and relational models. Cent Eur J Oper Res 26:1-41 
Zekić-Sušac M, Scitovski R, Lešaja G (2018) CEJOR special issue of Croatian operational research society. Cent Eur J Oper Res 26:531-534

Publisher's Note Springer Nature remains neutral with regard to jurisdictional claims in published maps and institutional affiliations. 